\section{TRINTA ANOS DE CLASSICA, A REVISTA BRASILEIRA DE ESTUDOS CLÁSSICOS}

\author{
THIRTY YEARS OF CLASSICA, THE BRAZILIAN \\ JOURNAL OF CLASSICAL STUDIES
}

Zelia de Almeida Cardoso*

Recebido em: 24/07/2019

Aprovado em: 13/08/2019

$\mathrm{N}$

o final de 1989, editado pelo Serviço de Artes Gráficas da Faculdade de Filosofia, Letras e Ciências Humanas da de Apoio a Publicações Científicas do CNPq/FINEP, despontava para o público o primeiro volume de Classica, Revista Brasileira de Estudos Clássicos, órgão oficial da SBEC, a Sociedade Brasileira de Estudos Clássicos. Tornava-se concreto, dessa forma, um dos projetos, alimentado desde a fundação da Sociedade: o de ter um veículo de difusão da produção científica não só de seus membros, mas também de outros reconhecidos pesquisadores que contribuíssem para a revista com trabalhos originais e inéditos.

A ideia da constituição de uma sociedade científica voltada para os estudos sobre a Antiguidade surgira em maio de 1984, quando foi realizado em Belo Horizonte o I Congresso Nacional de Estudos Clássicos. Promovido pelo Departamento de Letras Clássicas da Faculdade de Letras da UFMG, o evento recebeu o apoio de diversos órgãos da própria Universidade, bem como do $\mathrm{CNPq}$, que concedeu recursos, das Secretarias de Turismo de Minas Gerais e de Belo Horizonte, do Consulado da Itália, da Embaixada da Grécia e de várias outras entidades. Organizado por uma comissão liderada pelo Prof. Jacyntho Lins Brandão, e tendo por eixo temático "O mito de Édipo", o Congresso teve o condão de congregar pesquisadores oriundos da própria UFMG, e também da PUC-MG, da UFU, da UFOP, do CPM, da FFCLBH, do CSCJ-BH, da EGB, da FGV, da ESTEB-MG e, ainda, da USP, da UNESP, da UFRGS, da UFRJ, da UFF, da SUAM/ RJ. Reunidos durante uma produtiva semana nas dependências da
*Professora Titular Sênior de língua e literatura latina, Faculdade de Filosofia, Letras e Ciências Humanas, Universidade de São Paulo.

zlvdacar@usp.br 
UFMG, esses investigadores tiveram oportunidade de apresentar sua contribuição, discutir assuntos de interesse comum e apreciar resultados de pesquisas recentes, contando com a presença e a assistência de numerosos estudantes de graduação e pós. Muitos dos trabalhos lidos e debatidos focalizaram o tema central do evento; outros, porém, giraram em torno de motivos paralelos relacionados com a Antiguidade, sob o viés de diversas especialidades: arqueologia, antropologia, sociologia, psicologia, história, filosofia, mitologia, religiões, artes, línguas, literaturas.

Os textos disponibilizados deram origem a dois livros, publicados em 1984 e 1987 pela Imprensa Universitária da UFMG: O enigma em Édipo Rei, organizado por Jacyntho Lins Brandão, e Cultura clássica em debate, já com o apoio da SBEC, editado pelo mesmo organizador, em parceria com Neiva Ferreira Pinto. Essas publicações, bem como outras que derivaram de eventos e serão mencionadas adiante, estão disponibilizadas em pdf, na página da SBEC na internet, e podem ser acessadas por todos que por elas se interessarem.

$\mathrm{Na}$ sessão plenária, com a qual se encerrou o I Congresso, foi proposta a criação da almejada Sociedade Brasileira de Estudos Clássicos, que poderia ser legalmente fundada no ano seguinte, em Belo Horizonte, no âmbito da $37^{a}$ Reunião da SBPC que ali ocorreria. Durante o período que mediou entre esses dois momentos, foi elaborado o projeto do Estatuto da futura associação. As informações concernentes às atividades então realizadas foram veiculadas pelo Boletim de Estudos Clássicos, o BEC, um pequeno jornal xerocopiado, com notícias do interesse dos classicistas, que o Departamento de Letras Clássicas da Faculdade de Letras da UFMG enviou periodicamente aos participantes do I Congresso bem como às Universidades de que eram oriundos.

A fundação da Sociedade Brasileira de Estudos Clássicos ocorreu, conforme previsto, a 13 de julho de 1985, quando se aprovou o projeto do Estatuto, durante um encontro do qual mais uma vez participaram pesquisadores provenientes de diferentes regiões do país. Foi então constituída a primeira Diretoria e os primeiros Conselhos Administrativos, tendo sido eleita como primeira Presidente a Profa. Dra. Haiganuch Sarian, do MAE-USP, grande entusiasta da ideia da fundação da SBEC. Propôs-se a criação de Secretarias Regionais, estabeleceu-se que a Sociedade teria reuniões anuais, de caráter acadêmico, e organizaria um Congresso a cada cinco anos, agendou-se a realização de uma primeira reunião para o ano seguinte, em Curitiba, durante a $38^{a}$ Reunião da SBPC, e foi indicada uma Comissão Editorial que se encarregaria de planejar as normas de uma revista brasileira que tivesse por objeto a cultura que se desenvolveu na Antiguidade.

Em 1986, durante a semana de ampla programação acadêmica que caracterizou sua $1^{a}$ Reunião Anual, a SBEC, apoiada pelo CNPq, pela SBPC, pela UFMG e pela Transbrasil, começou a implementar seus objetivos e a desempenhar, a partir desse momento, um papel fundamental na difusão dos estudos clássicos no Brasil, promovendo importantes intercâmbios com todo o mundo, aglutinando interesses, envolvendo milhares de pessoas que se dedicavam ao estudo das sociedades antigas. Contou-se nos eventos, que então foram sendo promovidos, com a presença de investigadores provenientes de numerosas 
universidades não só do Brasil, mas também de países da América Latina, da América do Norte e da Europa.

As notícias referentes ao mundo antigo continuaram a ser difundidas pelo $B E C$ e foi planejado um opúsculo destinado a divulgar periodicamente trabalhos de membros da SBEC: os Textos de Cultura Clássica.

Nos primeiros anos de existência da Sociedade, algumas Secretarias Regionais, de acordo com as expectativas, não só coorganizaram os encontros científicos anuais em conjunto com as Diretorias, como realizaram, em suas regiões, seminários, simpósios, semanas de estudo, jornadas e cursos, com o apoio de unidades universitárias locais e contando muitas vezes com a colaboração de pesquisadores estrangeiros especialmente convidados, ou que ministravam disciplinas no país como professores visitantes. Entre os primeiros eventos promovidos por Secretarias Regionais, lembramos, à guisa de exemplificação, o I Congresso Estadual de Estudos Clássicos, ocorrido em Congonhas em 1986, o Colóquio "Fedra/Hipólito: a permanência de um mito", em Araraquara, também em 1986, o Curso "Cultura Grega Clássica" e os Seminários "Atualidade do Mito" e "As formas do épico", em Porto Alegre, em 1987.

Desses eventos resultaram publicações chanceladas pela SBEC: Fedra/Hipólito: a permanência de um mito clássico (Boletim da I Semana de Estudos Clássicos), Araraquara, UNESP/SBEC, 1987 (org. por Maria Celeste Consolin Dezotti); Cultura Grega Clássica, Porto Alegre, Editora da Universidade, 1989 (org. por Loiva Otero Félix e Miriam Barcellos Goettems); Mito Ontem e Hoje, Porto Alegre, UFRGS, 1990 (org. por Donaldo Schüler e Míriam Barcellos Goettems); As Formas do Épico: da epopeia sânscrita à telenovela, Porto Alegre, SBEC \& Movimento, 1992 (org. por Myrna Bier Appel e Míriam Barcellos Goettems).

As reuniões anuais da SBEC, realizadas a partir de 1987, embora se tivesse estabelecido que a cada quinquênio haveria um Congresso, tiveram, elas também, a configuração e a estrutura de verdadeiros congressos, verificando-se, a cada ano, maior afluência de participantes e um número crescente de apresentações de trabalhos sobre os diferentes ramos de especialização a que se dedicavam individualmente os classicistas. Em todos esses eventos, ao lado da substancial parte acadêmica, houve reuniões administrativas, sendo, de dois em dois anos, recompostos, por eleição da Assembleia Geral Ordinária, os Conselhos e a Diretoria. Os Presidentes, eleitos sucessivamente, foram: Daisi Malhadas (UNESP), em 1987; Donaldo Schüler (UFRGS) em 1989; Jacyntho Lins Brandão (UFMG), 1991; Maria das Graças de Moraes Augusto (UFRJ), 1993; Zelia de Almeida Cardoso (USP), em 1995; Carlos Alberto da Fonseca (USP), em 1997; Neiva Ferreira Pinto (UFJF), em 1999; Fábio Vergara Cerqueira (UFPel), em 2001; Neiva Ferreira Pinto (UFJF), em 2003; Fernando Brandão dos Santos (UNESP), em 2005; Markus Figueira da Silva (UFRN), em 2007; Henrique Fortuna Cairus (UFRJ), em 2009; Gabriele Cornelli (UnB), em 2011; Fábio Faversani (UFOP), em 2013; Paulo Martins (USP), em 2015; Tatiana Oliveira Ribeiro (UFRJ), em 2017; Ana Maria César Pompeu (UFC), em 2019.

A $2^{a}$ Reunião da SBEC, ocorrida em Belo Horizonte, em 1987, com apoio do CNPq e da Fundação Calouste Gulbenkian, de Portugal, foi sediada pela UFMG e definiu, 
praticamente, a estrutura das futuras reuniões. A conferência de abertura, "Mito, ironia e psicologia no Orestes de Eurípides", foi proferida por Maria Helena da Rocha Pereira, da Universidade de Coimbra. As sessões acadêmicas foram divididas em grupos temáticos, abordando os diversos campos de conhecimento abrangidos pelos estudos clássicos. Deles participaram pesquisadores da UFMG, UFRJ, UFF, UFC, UFRGS, UFRGN, UFJF, UFPB, UEPG, UVC, UnB, USP, UNICAMP, UNESP, FEFJP, PUC-SP, PUC-MG, PUC-RS, UnG, do Instituto Dante Alighieri/RJ, do Script Littera/RJ, da Universidade Gama Filho/RJ, bem como das Universidades de Boston, Tübingen e Louvain, além da de Coimbra. Três minicursos sobre temas clássicos foram oferecidos a estudantes.

As reuniões subsequentes, ocorridas em diversas cidades, em geral coadjuvadas por unidades universitárias locais, tiveram organização semelhante, tendo a duração de uma semana e constando de sessões de abertura e encerramento, da parte acadêmica com conferências, mesas-redondas, sessões de comunicações e minicursos, de reuniões de caráter administrativo, incluindo-se a da Assembleia Geral, sendo também oferecidas aos participantes algumas atividades culturais e artísticas.

A $3^{\text {a }}$ Reunião ocorreu no Rio de Janeiro, em julho de 1988, com efetivo apoio do CNPq, da ASESCC, da Amil e de diversos órgãos da UFRJ, onde ocorreu o evento. O tema previamente selecionado fora "Palavra e pensamento na Antiguidade Clássica". Arminda Lozano, da Universidad Complutense de Madrid, pronunciou na sessão de abertura a conferência intitulada "Movimentos de libertação de escravos no mundo grego helenístico". Outras onze conferências se distribuíram pelos demais dias, somando-se a 14 mesas-redondas, 63 comunicações e 6 minicursos. Como atividades artísticas, foram proporcionadas aos congressistas leituras dramáticas de textos clássicos e um recital de violão.

O II Congresso Nacional de Estudos Clássicos se realizou em 1989, em São Paulo, nas dependências da USP, conjuntamente com a $4^{a}$ Reunião da SBEC. O tema, antecipadamente escolhido para o evento, havia sido "Mito, religião e sociedade". Acentuou-se a presença de pesquisadores estrangeiros. Além de seis conferencistas brasileiros, convidados a participar do Congresso por sua alta qualificação - Alfredo Bosi (USP), José Cavalcante de Souza (USP), Ciro Flammarion Cardoso (UFF), Donaldo Schüler (UFRGS), Antônio da Silveira Mendonça (USP/Unicamp) e Izidoro Blikstein (USP) -, oito pesquisadores do exterior pronunciaram conferências: Michele Coccia (Università di Roma), Martin L. West (University of London), Mireille Corbier (CNRS-Paris), Filippo Coarelli (Università di Perugia), José Nunes Carreira (Universidade de Lisboa), José Riquelme Otálora (Universidad de Zaragoza), Madeleine Biardeau (Université de Paris) e Olivier Reverdin (Fondation Hardt - Suíça). Três pesquisadoras de universidades argentinas compareceram ao evento, como delegadas de suas instituições de origem, trazendo credenciais e estabelecendo o início de um profícuo trabalho de intercâmbio entre os dois países.

Ao lado das conferências, foram apresentadas, durante o Congresso, 62 comunicações coordenadas, 56 comunicações individuais e 3 mesas-redondas. Desses trabalhos, 64 vieram a constituir o Livro de Atas, intitulado Mito, religião e sociedade, organizado por Zelia de Almeida Cardoso e publicado em 1991 pelo Serviço de Artes Gráficas da FFLCH/ 
USP, com recursos concedidos por VTTAE Apoio à Cultura, Educação e Promoção Social. Os 3 minicursos destinados aos alunos tiveram frequência bastante satisfatória. As atividades artísticas ficaram sob responsabilidade da Orquestra Sinfônica da USP, que participou da Sessão de Abertura, do Coralusp, que se apresentou na Sessão de Encerramento, e do Grupo "Giz-en-Scène" que fez leituras dramáticas de um poema védico, do Filoctetes, de Sófocles, e de Os Menecmos, de Plauto.

Durante o evento, que contou com o apoio da USP, do CNPq, da FAPESP, dos Bancos do Brasil, Itaú e Caixa Econômica Federal, e de algumas empresas privadas, tais como a Klabin, a Metal Leve, a Nestlé e a São Paulo Indústrias Gráficas, as reuniões administrativas se realizaram normalmente, inclusive a primeira reunião do Conselho Editorial, que havia sido constituído em janeiro de 1989.

Durante esses anos, o BEC continuou a circular, publicaram-se doze números de Textos de Cultura Clássica e, entre o fim de 1989 e o início de 1990, foram enviados aos sócios os volumes 1 e 2 da revista Classica, correspondentes aos anos de 1988 e 1989, finalmente editados, embora com algum atraso, graças a recursos concedidos pelo Programa de Apoio a Publicações Científicas do CNPq/FINEP.

Classica, a revista da SBEC, foi criada para ser um periódico de caráter científico e cultural, que deveria divulgar trabalhos originais e inéditos que tivessem por escopo os vários aspectos das culturas da Antiguidade clássica, sem, no entanto, excluir outras sociedades antigas do Velho Mundo. De caráter interdisciplinar, procuraria promover o diálogo entre as diversas disciplinas que, de uma forma ou outra, se ocupam dos estudos clássicos.

O primeiro volume de Classica, impresso no Serviço de Artes Gráficas da FFLCH/ USP, foi organizado por uma Comissão Editorial, conforme as previsões. Compunha-se de dez artigos de natureza científica e de três resenhas críticas, perfazendo um total de 167 páginas. Foram autores desses trabalhos pesquisadores filiados à SBEC ou vinculados a importantes centros de investigação científica. Atesta a vocação internacionalizante da Sociedade a colaboração de autores estrangeiros, tais como Nikolaos Yalouris, antigo diretor do Serviço de Antiguidades e do Museu Nacional de Atenas, René Ginouvès, da Universidade de Paris, e Christian Jacob, do CNRS de Paris.

O volume 2, correspondente a 1989, também foi impresso no Serviço de Artes Gráficas da FFLCH/USP. Constando de doze artigos e duas resenhas, divulgou textos de pesquisadores de São Paulo, Minas Gerais, Rio Grande do Sul, Rio de Janeiro e Brasília, fomentando-se mais uma vez o frutífero intercâmbio proporcionado por estudiosos consagrados a investigações sobre a Antiguidade.

Em 1990 realizou-se no Rio Grande do Sul, em Garibaldi, a 5 ${ }^{\text {a }}$ Reunião da SBEC, cujo eixo temático era "Vinho e pensamento". Com apoio da Prefeitura local e da UFRGS, e também do CNPq, da CODEC/RS, do Banrisul e da FAPERGS, a Reunião registrou, como nas anteriores, afluência de participantes bastante significativa, salientando-se a presença de 21 investigadores argentinos provenientes das Universidades Nacionais de Buenos Aires, Rosário e La Plata, e da Universidad Católica Argentina. Sete minicursos foram facultados aos estudantes e numerosos trabalhos acadêmicos foram apresentados, perfazendo um total 
de 72 comunicações individuais e 35 comunicações coordenadas. Trinta desses trabalhos foram coligidos no livro intitulado Vinho e pensamento, organizado por Nely Maria Pessanha e Vera Regina Figueiredo Bastian, da UFRJ, e publicado, em 1991, pela Editora Tempo Brasileiro e pela SBEC, com o apoio da Prefeitura de Garibaldi.

A $6^{a}$ Reunião, realizada em 1991, em conjunto com o IV Simpósio de Estudos Clássicos e Medievais, com promoção da SBEC e da UFMG, ocorreu mais uma vez em Belo Horizonte, contando-se com o apoio do CNPq, da FAPEMIG e de várias empresas privadas. As atividades acadêmicas envolveram, como já de costume, conferências, mesas-redondas, sessões de comunicações e minicursos. As conferências e mesas-redondas ficaram a cargo de pesquisadores convidados, do país e do exterior: Giuseppina Grammatico (UMCE-Santiago), Esther Paglialunga (Universidad de los Andes), Donaldo Schüler (UFRGS), Elisabeth Caballero de del Sastre (UBA), Marilda Ceribelli (UFRJ), José Heck (UFG), Marcel Pacaut (Université de Lyon), Haiganuch Sarian (USP), François Jouan (Université de Paris), Daniel Valle Ribeiro (UFMG) e Nachman Falbel (USP). As sessões de comunicações, com um total de 108 trabalhos inscritos, constituíram nove GTs, abrangendo as múltiplas especialidades dos participantes. Uma seleção dos textos apresentados, organizada por Jacyntho Lins Brandão e Tereza Virgínia Ribeiro Barbosa, foi publicada em 1992 no Suplemento 1 de Classica, com apoio do CNPq e da FAPEMIG.

Como atividades artísticas da $6^{a}$ Reunião, houve um concerto de piano e flauta, na sessão de abertura, uma adaptação livre de tragédias de Ésquilo e Eurípides, levada à cena pela Companhia Teatral "Mergulho no Trágico", uma leitura dramática, conduzida pelo Grupo "Giz-en-Scène", e uma performance com serestas, executada pelo Conjunto Diamantina.

Em 1991, o volume 3 de Classica, correspondente ao ano de 1990, foi publicado pela Imprensa Universitária da UFMG, com apoio financeiro da Fundação VITAE, apresentando sete artigos agrupados em dois eixos temáticos: "Ciência, filosofia e sociedade no mundo antigo" e "Classicismo e modernidade". Ao lado dos artigos e de cinco resenhas críticas, foram criadas novas seções, destinadas a comunicações, notas e comentários, bem como a crônicas, instrumentos de pesquisa, notícias e ensaios bibliográficos. Contou-se nesse número, além de trabalhos elaborados por pesquisadores da UFRJ, USP, UFMG, UFOP, UFF, UNESP, UFRGS e Universidade Santa Úrsula, filiados à SBEC, com colaborações de investigadores do exterior tais como Sally C. Humphreys, do University College, de Londres, com o texto de sua conferência "Philosophy and religion in Greece", pronunciada anteriormente na UFMG e traduzida por Lúcia Las Casas e Jacyntho Lins Brandão; Juan Miguel de Mora, da UNAM; Suzanne Gély, da Université Paul Valéry, de Montpellier, Antonio Piñero, da Universidad Complutense de Madri; Christian Jacob, do INRS; e Maria Helena da Rocha Pereira, da Universidade de Coimbra.

O volume 4 da revista Classica, correspondente a 1991, foi editado no final desse ano, com o apoio da Editora Paz e Terra e do CNPq/FINEP. Dessa vez, em lugar de um eixo temático genérico, como ocorrera anteriormente, houve dois temas para nortear a produção de artigos: "Adivinhação no mundo antigo" e "Classicismo e modernidade". Treze ensaios versaram sobre tais assuntos, unindo-se a trabalhos relacionados com as demais seções da 
revista: ensaio bibliográfico; instrumentos de pesquisa; resenhas críticas. Como nos volumes anteriores, além de contribuições de classicistas brasileiros, muitos dos quais filiados à SBEC, contou-se com a colaboração de pesquisadores estrangeiros: Jean Bottéro, da École Pratique des Hautes Études de Paris V, cujo estudo "Divination et esprit critique" foi traduzido por Filomena H. Hirata sob o título "Adivinhação e espírito crítico na Mesopotâmia"; Juan Diego Vila, da Universidad de Buenos Aires; Elina Miranda, da Universidad de La Habana; François Jouan, da Université de Paris X, Nanterre.

Em 1992, com promoção conjunta da Sociedade Brasileira de Estudos Clássicos e da UNESP, foi realizada em Araraquara a $7^{\text {a }}$ Reunião Anual da SBEC. Uma vez que se comemorava nesse ano o bimilenário de Horácio e o quinto centenário da descoberta da América, foram dois os eixos temáticos escolhidos: "Horácio: dois mil anos" e "Viagens e descobrimentos". O evento constou de 15 conferências, 9 minicursos e 145 comunicações, que foram agrupadas em mesas-redondas e GTs. À conferência inaugural de Pierre Lévêque, da Université de Besançon, se acrescentaram as que foram pronunciadas por pesquisadores convidados: Alceu Lima (UNESP), Elisabeth Caballero de del Sastre (Universidad de Buenos Aires), Haiganuch Sarian (USP), Jacyntho Lins Brandão (UFMG), Giusto Monaco (Istituto Nazionale del Dramma Antico), Zelia de A. Cardoso, Erasmo A. Magalhães (USP), Monique Clavel-Lévêque (Université de Besançon), Carlo Santini (Università degli Studi di Perugia), Carmelo Distante (USP), José A. Dabdab Trabulsi (UFOP) e Carlos Alberto da Fonseca (USP). Apresentaram comunicações pesquisadores provenientes da UNESP, USP, UFRJ, UFPR, UFPB, UFF, UNICAMP, FUEM, USU, UFRGS, FATEC, UFOP, UNB, FURG, UFES, FNB, UFJF, FCJA, FUNREI, bem como da UBA, UNLP, UNRos, Unipan, Conicet e UnLaPampa, universidades argentinas. Os trabalhos apresentados, dos quais grande parte se filiou aos eixos temáticos, exploraram também outros filões, que forneceram o temário dos GTs: "Linguística e filologia", "Literatura latina e grega", "História", "Filosofia", "Arqueologia", "Intertextualidade". As reuniões administrativas decorreram dentro da normalidade esperada. As atividades artísticas constaram de leituras dramatizadas de textos clássicos e de apresentações de um espetáculo lítero-musical, de números de balé e danças gregas, de peças teatrais, e de uma "noite de seresta".

A SBEC recebeu o apoio do CNPq, da FAPESP, do FUNDUNESP e também de empresas como Nigro, Cutrale e Lupo, o que permitiu não só a realização do evento como a futura publicação de uma seleção de trabalhos apresentados no Suplemento 2 de Classica, organizado por Sílvia Maria S. de Carvalho, Edvanda Bonavina da Rosa, Fernando Brandão dos Santos e José Dejalma Dezotti, e publicado em 1993.

A $8^{a}$ Reunião Anual da SBEC, subordinada ao tema "Linguagem e poder na Antiguidade Clássica”, realizou-se em 1993, em Niterói, com o apoio do CNPq, da FAPERJ, da UFF, da UFRJ, do Unibanco, da Amil e da Swains Arte. O evento se organizou como de praxe. A sessão de abertura, além de contar com as palavras de boas-vindas de autoridades da UFF e da SBEC, proporcionou aos presentes a oportunidade de ouvir mais uma vez uma conferência de Maria Helena da Rocha Pereira, da Universidade de Coimbra, e de assistir a uma apresentação do Coral da UFF. A essa conferência se somaram as que foram 
pronunciadas, durante o evento, por Giuseppina Grammatico, da UMCE (Chile), Ciro Flamarion (UFF), e Emmanuel Carneiro Leão (UFRJ). As 140 comunicações inscritas foram distribuídas por doze grupos de trabalho, conforme sua especificidade, e seis minicursos foram oferecidos aos alunos.

Nesse evento, em virtude das dificuldades econômicas que o país vinha enfrentando e dos problemas para a realização de suas atividades, foi proposta e aprovada pela Assembleia Geral Ordinária uma alteração do cronograma até então adotado. Em vez de uma Reunião Anual, a SBEC promoveria Reuniões Bienais e os congressos passariam a ocorrer de seis em seis anos. Agendou-se para 1995 a 9 a Reunião, que aconteceria no Rio de Janeiro, conjuntamente com o III Congresso Nacional de Estudos Clássicos.

Entre 1993 e 1995 algumas publicações da SBEC foram implementadas. Os Textos de Cultura Clássica receberam novo projeto gráfico, tornando-se Maria das Graças de Moraes Augusto a editora responsável, e foi criado o BLAEC (Boletim Latino-Americano de Estudos Clássicos), periódico informativo da responsabilidade da SBEC, em conjunto com a AADEC (Asociación Argentina de Estudios Clásicos) e com a SCEC (Sociedad Chilena de Estudios Clásicos), financiado pela União Latina e tendo Jacyntho Lins Brandão como editor responsável.

Foram também publicados, em 1993, condensados num único volume, os volumes 5 e 6 de Classica, correspondentes a 1992 e 1993. A condensação de dois volumes em um e a publicação bienal foram medidas que passaram a ser empregadas até 2005, como a forma encontrada pelo Conselho Editorial para amenizar dificuldades técnicas e financeiras decorrentes da publicação anual.

Impresso nas oficinas da Gráfica Palas Atena, com recursos do Programa de Apoio a Publicações Científicas do CNPq/FINEP, bem como do MCT, da União Latina e do Fundo Pro Classica, o volume 5/6 apresentou dois eixos temáticos - "Filosofia, literatura, história e antropologia" e "Classicismo e modernidade" - aos quais se filiaram 13 artigos compostos por pesquisadores do país (USP, UNICAMP, UNESP, UFMG, UNB) e do exterior: Universidad Metropolitana de Ciencias de la Educación, de Santiago de Chile; Universidad de Buenos Aires; Université de Franche-Comté (Besançon); Centre National de la Recherche Scientifique (Paris).

No setor reservado aos instrumentos de pesquisa, num momento em que a informática começava a desenvolver-se aceleradamente, a Arqueologia foi contemplada com quatro textos, escritos por especialistas que focalizaram novas metodologias, tendo contado a revista com a contribuição de investigadores do Ministère de la Recherche et de l'Enseignement Supérieur e do Centre National de la Recherche Scientifique, de Paris, da Union Minière, de Bruxelas, e do Centre d'Automatique et d'Informatique da École Nationale Supérieure des Mines de Paris. Os trabalhos por eles oferecidos a Classica foram traduzidos por pesquisadores do MAE-USP.

Em 1995, quando se comemorava o $10^{\circ}$ aniversário da Sociedade, realizou-se, na UFRJ, conforme previsto, o III Congresso Nacional de Estudos Clássicos, conjuntamente com a 9a Reunião da SBEC, sendo o eixo temático "As representações da Antiguidade Clássica". 
Na sessão de abertura, Peter Wülfing, da Universidade de Colônia, pronunciou a conferência inaugural. As atividades acadêmicas foram divididas em seminários, apresentações de GTs e sessões de comunicações livres. Para cada seminário foram convidados dois expositores, tendo sido as exposições seguidas de debates. Os GTs, para os quais houve inscrição antecipada, consistiram em discussões de textos inscritos, distribuindo-se aos participantes, sob a forma de cadernos impressos, os que seriam discutidos. As comunicações livres, em pequeno número, corresponderam a exposições de trabalhos cujo assunto não se filiava aos temas dos GTs.

Quatro minicursos foram ministrados e, no último dia, houve uma mesa-redonda sobre os estudos clássicos na América Latina, coordenada por Maria das Graças de Moraes Augusto, da qual participaram Giuseppina Grammatico (UMEC - Chile), Jacyntho Lins Brandão (UFMG - Brasil), Ester Paglialunga (Universidad de los Andes - Venezuela) e Rodolfo Pedro de Buzón (UBA - Argentina).

Algumas unidades universitárias do exterior e do país se fizeram representar nesse Congresso pela primeira vez, por meio de pesquisadores que apresentaram trabalhos. Foi o caso da Universidade de Indiana (USA), da UNAM (México), da Universidad de Tucumán (Argentina) e das seguintes universidades nacionais: UFMS, UERJ, PUC/CAMP, UFBA, UEM, PUC/RJ, UFV. Essas unidades universitárias se acrescentaram àquelas que, desde a fundação da SBEC, vinham participando de seus eventos com assiduidade e brilho.

Destaca-se, nesse biênio, o lançamento do segundo número do $B L A E C$, do $17^{\circ}$ de Textos de Cultura Clássica e do volume 7/8 de Classica, correspondente a 1994 e 1995, com o eixo temático "A morte, os mortos no mundo antigo". A esse eixo se vincularam 14 artigos que se somaram a 9 outros, definidos pela indicação "Outros temas sobre a Antiguidade Clássica", e a 4 sobre "Classicismo e Modernidade". Nas seções destinadas a "comunicações e notas", "instrumentos de pesquisa", "ensaio bibliográfico" e "resenhas", contou-se com várias colaborações.

Em 1996, para divulgar a $10^{a}$ Reunião que seria realizada em 1997, bem como outras atividades promovidas pela Sociedade, foi criado um folheto de informações, o Informativo SBEC. Esse folheto perdurou até 2002, veiculando notícias de interesse geral para os classicistas, tais como promoção de eventos no país e no exterior, concursos, atividades dos sócios, defesas de monografias e teses, publicação de livros e revistas, e outros assuntos relacionados com os estudos clássicos. Enviado periodicamente aos sócios por correio, foi posteriormente inserido na primeira página de que a SBEC passou a dispor na internet, sediada pelos serviços de hospedagem de sites denominados Ex machina e Geocities.

A $10^{a}$ Reunião da SBEC, tendo por tema "Escrita e oralidade na Antiguidade Clássica", foi realizada em São Paulo, em 1997, com apoio da USP, contando-se com recursos concedidos pelo CNPq, FAPESP e União Latina. Para participarem do evento foram convidados 11 conferencistas, dos quais 7 eram provenientes de instituições estrangeiras (François Paschoud, da Université de Genève, que pronunciou a conferência inaugural, na sessão de abertura, intitulada "Sources écrites, sources orales dans l'historiographie de l'Antiquité tardive"; Jackie Pigeaud, da Université de Nantes, Walter Burkert, da Universidade de Zurique, Alfredo Eduardo Fraschini, da Universidad de Buenos Aires, Roland Etienne, Philippe Bruneau e 
Michèle Brunet, da École Française d'Athènes) e três de universidades brasileiras (Donaldo Schüler, da UFRGS, José Cavalcante de Souza e Norberto Luiz Guarinello, da USP). Foram ministrados 9 minicursos, dos quais 5 por 6 pesquisadores convidados (Maria de Fátima Silva e Sebastião Pinho, da Universidade de Coimbra; Rodolfo Pedro Buzón e Pablo Adrián Cavallero, do CONICET-UBA; Ana Maria de Tobia, da Universidad Nacional de La Plata; José Riquelme Otálora, da Universidad de Zaragoza) e 4 por docentes do país (Henrique Graciano Murachco, da USP; Jorge Ferro Piqué, da UFPR; Anise A. G. D’Orange Ferreira, da USP; Tereza Virgínia R. Barbosa, da UFMG; e Maria Isabel D’A. Fleming, da USP). Inscreveram-se 66 participantes para 15 sessões de comunicações coordenadas e 125 para 32 mesas de comunicações livres; e houve uma mesa-redonda dedicada especialmente a trabalhos de Arqueologia, na qual se contou com a presença de dois especialistas: Emanuel Bouzon, da PUC-Rio, e René Treuil, da Université de Paris 1. Apresentaram-se 330 trabalhos acadêmicos, muitos dos quais foram posteriormente publicados como artigos em Classica 11/12 e 13/14, correspondentes a 1998/1999 e 2000/2001, cujos temas foram, respectivamente, "Escrita e oralidade na Antiguidade Clássica" e "Imagem e discurso no mundo antigo".

Como atividades complementares, houve um recital de piano, a cargo de Valdilice de Carvalho, uma mesa-redonda sobre "A escrita no Mundo Antigo" - realizada no MAE-USP, durante dois dias, com participação de dez palestrantes -, uma exposição de documentos, folders e publicações da SBEC, e um lançamento de livros.

Em 1997, foi editado o volume 9/10 de Classica, correspondente a 1996 e 1997, com 11 artigos vinculados ao tema central, "Jogos e espetáculos no mundo antigo", 4 referentes a "Outros temas sobre a Antiguidade" e outros 4 a "Classicismo e modernidade", tendo sido também publicados dois textos concernentes à seção denominada "instrumentos de pesquisa", um ensaio bibliográfico e oito resenhas críticas.

A $11^{a}$ Reunião da SBEC ocorreu em 1999, na UNESP, no campus de Araraquara. Como em eventos anteriores, contou-se com recursos oferecidos pelo CNPq e pela FAPESP e com o apoio de várias empresas privadas e bancos. Ao eixo temático "Arte, saber e cidadania na Antiguidade Clássica" filiou-se grande parte dos mais de 200 trabalhos apresentados como comunicações coordenadas ou livres. As conferências ficaram a cargo de pesquisadores convidados (Maria Sylvia de Carvalho Franco e Luiz Marques, da Unicamp; Henrique Graciano Murachco e Sérgio Mascarenhas, da USP; Alceu Dias Lima, da UNESP; François Hartog, da EHESS; Juan Miguel de Mora, da UNAM; Rodolfo Buzón, da UBA; e Paulo Butti de Lima, da Università di San Marino); e 10 minicursos foram ministrados. Além das reuniões administrativas, dois importantes encontros foram inseridos no evento: o da "International Plato Society" e o do "Projeto Apollonia"; houve ainda demonstrações do "Centro de Estudos Lexicográficos", do "Centro Virtual de Estudos Clássicos" e da home page "Grécia Antiga". Como atividades complementares, o evento proporcionou aos congressistas exibições de filmes sobre temas clássicos, seguidos de debates, leituras de peças apresentadas pelo Grupo "Giz-en-scène”, e espetáculos teatrais.

Tendo por tema "Antiguidades", o IV Congresso Nacional de Estudos Clássicos ocorreu em 2001, em Ouro Preto (MG), na UFOP, conjuntamente com a $12^{a}$ Reunião da 
SBEC. Foram inscritos para apresentação mais de 350 trabalhos. Quatro pesquisadores convidados pronunciaram conferências: Jaume Pòrtulas Ambrós, da Universidade de Barcelona; Haiganuch Sarian, da USP; Annie Artaud-Portelli e Pascal Arnaud, da Universidade de Nice. A essas conferências se somou a de encerramento, proferida por Neiva Ferreira Pinto. Chamou a atenção, no evento, a quantidade de minicursos ministrados: 12, sobre diversos assuntos, sendo dois por professores estrangeiros (Lia Galán, conjuntamente com Maria Delia Buisel, da ULP; e Blanca A. Quiñonez, da UNT), e 10 por docentes vinculados a unidades universitárias brasileiras (Elaine Farias Veloso Hirata, do MAE-USP; Daisi Malhadas, da UNESP; André Bueno, da UFF; Arlete José Mota, da UFRJ; Álvaro Alfredo Bragança, da UFRJ; Maria Aparecida de Oliveira Silva, da USP; Markus Figueira da Silva, da UFRN; Maria Beatriz Borba Florenzano, da USP; Luís Carlos Lima Carpinetti, da UFJF; e Anise A. G. D’Orange Ferreira, da USP). Oito painéis, com amostras da produção científica do país, foram expostos no hall do Centro de Convenções, onde se realizaram as atividades acadêmicas. Inspirado possivelmente no tema do evento, foi organizado posteriormente um concurso de fotos de ruínas e monumentos antigos e, com as fotografias premiadas, montouse um álbum, intitulado Um olhar sobre a Antiguidade clássica, organizado por Antônio Martinez de Rezende, Heloísa Maria Moraes Moreira Penna e Tereza Virgínia Ribeiro Barbosa, da UFMG, e publicado pela Sociedade.

A $13^{a}$ Reunião da SBEC, conjuntamente com o V Congresso Nacional de Estudos Clássicos, subordinado ao tema "Fronteiras e etnicidade", ocorreu no Rio Grande do Sul, em Pelotas, em 2003, como promoção conjunta da Sociedade com a UFPel, a UCPel, a UFRGS, a Ulbra, a UniRitter e a PUC-RS, tendo patrocínio da CAPES, da FAPERGS, do Instituto Camões, do Banco do Brasil e da Prefeitura de Pelotas.

Divulgado pela internet e por meio de circulares, o Congresso teve programação intensa, com conferências pronunciadas por pesquisadores convidados (José d'Encarnação, da Universidade de Coimbra; Cécile Michel, do CNRS/França; Ciro Flamarion Cardoso, da UFF), palestras, mesas-redondas, sessões de comunicações, minicursos e painéis. Como atividades culturais complementares, foram oferecidos aos congressistas números musicais e representações teatrais.

Muitos dos trabalhos apresentados foram coligidos no livro Fronteiras e etnicidade no Mundo Antigo, organizado por Chimene Kuhn Nobre, Fabio Vergara Cerqueira e Katia M. P. Pozzer, e publicado em 2005 pela Editora e Gráfica Universitária UFPel.

Durante a reunião da Assembleia Geral Ordinária, lembrou-se que no ano seguinte a nova Diretoria eleita teria a incumbência de coorganizar o XII Congresso da FIEC (Fédération Internationale des Associations d'Études Classiques), que já estava sendo preparado e que ocorreria em Ouro Preto.

Promovido pela FIEC e pela SBEC, e apoiado por diversas unidades universitárias brasileiras (UFMG, USP, UFOP, UNESP, UFJF e UFRJ), o XII Congresso da FIEC foi planejado com a necessária antecedência, recebeu recursos de financiadoras nacionais e estrangeiras, bem como de fundações, institutos e embaixadas, e ocorreu em 2004. Foram programadas duas conferências - de abertura e encerramento -, 15 mesas-redondas, cada 
uma das quais contando com a participação de 4 pesquisadores especialmente convidados, e 64 sessões de comunicações. Exibiram-se 86 painéis, com amostras da produção brasileira em estudos clássicos. Foram proporcionadas aos congressistas várias atividades culturais durante o evento: exposições de gravuras, desenhos e fotos, apresentação de choros e corais, mostra de curtas-metragens. Na sessão de encerramento, após a conferência de Annie Bélis, do CNRS de Paris, subordinada ao título "Chante pour les Muses et pour moi: esthétique musicale de l'Antiquité grecque et romaine", o Ensemble Kérylos, de Paris, sob a direção da conferencista, se apresentou com 10 peças musicais para cuja execução foram utilizadas réplicas de instrumentos gregos e romanos. Foi, sem dúvida, o maior empreendimento da SBEC em toda a sua existência: um Congresso com a presença de 60 convidados, a maioria dos quais provenientes de unidades universitárias do exterior, com a apresentação de mais de 300 trabalhos científicos, e com centenas de pessoas inscritas.

O volume 15/16 de Classica, correspondente ao biênio 2002/2003, foi publicado nessa ocasião, tendo como eixo principal o tema "Visões da Antiguidade", ao qual se vincularam 10 artigos. Nove abordaram outros temas sobre a Antiguidade e 5, questões referentes às relações entre classicismo e modernidade. Duas resenhas críticas completaram o volume.

A $14^{a}$ Reunião da SBEC, então denominada VI Congresso Nacional de Estudos Clássicos, foi realizada em 2005, no campus da Praia Vermelha da UFRJ e marcou o $20^{\circ}$ aniversário da instituição. O evento, cujo eixo temático era "Memória e festa", ocorreu conjuntamente com o XV Ciclo de Debates em História Antiga, promovido pelo LHIA/UFRJ, e teve o apoio da UNIRIO, da UERJ e da UFF, além do patrocínio do CNPq, da CAPES, da FAPERJ, do Banco do Brasil, da NEASPOC/UFOP e da MAUAD Editora.

As atividades acadêmicas desenvolvidas no Congresso, como acontecera em eventos anteriores, foram agrupadas em 10 mesas de palestras, cada uma com 3 palestrantes, 42 sessões de comunicações coordenadas, cada uma com 3 expositores, e 30 sessões de comunicações livres. Treze minicursos foram oferecidos aos alunos e 5 conferências foram proferidas por pesquisadores convidados: Neyde Theml (UFRJ), Ana María González de Tobía (Universidad de La Plata), Jacyntho Lins Brandão (UFMG), Nely Maria Pessanha (UFRJ) e Barbara Cassin (CNRS-Paris).

De todos esses trabalhos, 81 foram encaminhados para a publicação, tendo sido coligidos e organizados por Fábio de Souza Lessa e Regina Maria da Cunha Bustamante e publicados em 2005, no Rio de Janeiro pela Editora Mauad, sob o título Memória e festa.

Como atividades artísticas, houve durante o Congresso apresentações da Escola de Música da UFRJ e do Coral do CIEP “Operário Vicente Mariano”.

Nesse ano, os sócios da SBEC receberam o volume 17/18 de Classica, correspondente ao biênio 2004/2005, cujo tema central era "Imagens do mundo clássico". O volume apresentou 20 artigos, 4 trabalhos sobre instrumentos de pesquisa e uma resenha crítica.

Em 2007, as Reuniões e Congressos foram renumerados e renomeados, tendo sido postos em ordem numérica a partir do I Congresso Nacional de Estudos Clássicos, ocorrido em 1984, na UFMG, e passando a ser designados por "Congressos da SBEC". A $15^{\mathrm{a}}$ Reunião, realizada nesse ano na Faculdade de Ciências e Letras da UNESP, no campus 
de Araraquara, o XVI Congresso Nacional da SBEC, teve por tema "Ócio e trabalho no mundo antigo". Dez pesquisadores convidados proferiram conferências: Maria de Fátima Sousa e Silva, da Universidade de Coimbra, que pronunciou a conferência inaugural intitulada "Tarefas femininas e estatuto social na tragédia de Eurípides"; Jacyntho Lins Brandão, da UFMG; João Ângelo Oliva Neto, Haiganuch Sarian e Carlos Alberto da Fonseca, da USP; Pedro Paulo Abreu Funari, da Unicamp; Phillipe Rousseau, da Université de Lille; Ana María González de Tobía, da Universidad Nacional de La Plata; Fernando Tola e Carmen Dragonetti, também da Argentina.

As reuniões administrativas dos conselhos e comissões especiais da SBEC ocorreram normalmente e a Assembleia Geral Ordinária, além de recompor, como de costume, os novos Conselhos e eleger a nova Diretoria para os dois anos seguintes, aprovou uma decisão anterior pela qual a SBEC aporia seu selo ao Grupo InfoClassicas, monitorado com grande competência e dedicação por Henrique Cairus, garantindo a comunicação rápida entre os sócios, informando-os sobre congressos, concursos, chamadas de artigo, editais, e transmitindo-lhes outras notícias.

No biênio 2006/2007, a SBEC passou a contar também, efetivamente, com uma nova página na internet e a revista Classica foi reestruturada quanto ao aspecto periódico e formal. Em vez de continuar a ser bienal, como vinha ocorrendo desde 1996, passou a ser semestral, com os volumes divididos em dois números, com paginação sequencial; o formato $17 \times 24$ foi reduzido para 13×21; deixou de haver um eixo temático central e as matérias passaram a concentrar-se em três seções: artigos, artigos de revisão e resenhas. Com essas características, os sócios da SBEC receberam, em 2006, os números 1 e 2 do volume 19, e, em 2007, os números 1 e 2 do volume 20, contendo, todos eles, artigos, notas e resenhas. Em 2008, foram publicados os números 1 e 2 do volume 21, e, em 2009, os números 1 e 2 do volume 22.

O XVII Congresso da SBEC - embora denominado na ocasião "XVII Congresso Nacional de Estudos Clássicos" - ocorreu em 2009, em Natal, com o patrocínio do CNPq e da CAPES, nas dependências da UFRN, que estava comemorando seus 50 anos de existência, sendo "A amizade e o prazer no mundo antigo" o eixo temático que conduziu os trabalhos acadêmicos. Foi a primeira vez que a Sociedade Brasileira de Estudos Clássicos realizou seu encontro bienal na região Nordeste, tendo sido esse fato considerado extremamente promissor.

O Congresso foi organizado de forma um pouco diferente da dos eventos anteriores. Os 5 minicursos propostos foram ministrados no primeiro horário da manhã, durante toda a semana. Além da conferência inaugural, na sessão de abertura, e das duas que foram proferidas na cerimônia de encerramento, houve 3 ou 4 conferências todos os dias, no período matutino, pronunciadas por pesquisadores convidados, de numerosas universidades: UFMG, USP, UFG, UFOP, UFRJ, UNESP, UFRGS, UFPR, UFJF, UFBA, UnB, bem como Université de Paris, University of Toronto, Institut Universitaire de France, Università de Trieste, UNAM (México), Université de Rennes, UniRoma e Université d'Ottawa. Muitas dessas unidades universitárias estavam sendo representadas pela primeira vez em um evento 
da SBEC. Nos finais da manhã, realizaram-se as reuniões dos Conselhos (Consultivo, Fiscal e Editorial) e dos Secretários Regionais, tendo-se decidido que as Secretarias Regionais seriam então substituídas por Grupos de Trabalho que se filiassem à SBEC. No período vespertino, apresentaram-se 10 mesas-redondas, 17 mesas de comunicações coordenadas e 46 de comunicações livres. As atividades culturais contaram com a participação da Escola de Música da UFRN e do Grupo "Giz-en-Scène", com a leitura do Díscolo, de Menandro.

O XVIII Congresso da SBEC ("XVIII Congresso Nacional de Estudos Clássicos", conforme os documentos então emitidos), cujo tema foi "Antiguidade: performance e recepção", ocorreu em 2011, no Rio de Janeiro, e foi sediado no Instituto de Filosofia e Ciências Sociais da UFRJ, com o envolvimento de importantes instituições, tais como a Academia Brasileira de Letras, o Real Gabinete Português de Leitura, a Escola de Música da UFRJ e a Biblioteca Nacional, que participaram da organização e da realização do evento.

O Congresso decorreu dentro das expectativas. As atividades acadêmicas compreenderam conferências, mesas-redondas temáticas, sessões de comunicações coordenadas e individuais, e minicursos. As conferências foram proferidas por pesquisadores convidados, provenientes de instituições do exterior: Claude Calame, da EHESS (Paris) e da Université de Lausanne (Suíça), responsável pela conferência de abertura; Carlos Lévy, da Université de Paris IV (Sorbonne); Barbara Cassin, da Université de Paris IV e do CNRS; Marc Baratin, da Université de Lille. As 27 mesas-redondas, cada uma com seu tema específico, congregaram 69 palestrantes que fizeram seus pronunciamentos e participaram de debates. As 36 sessões de comunicações coordenadas, cada uma com 3 ou 4 participantes, se somaram a 55 de comunicações individuais, cada uma também com 4 participantes, perfazendo-se um total de 364 comunicações. Doze minicursos foram oferecidos aos estudantes e 44 painéis foram expostos, uma amostra da produção estudantil na área de estudos clássicos. Realizaramse também, no âmbito do Congresso, reuniões da ANPOLL, da ANPOF e da ANPUH.

Como atividades culturais, além de uma visita a uma exposição de livros raros sobre temas clássicos, oferecida pela Biblioteca Nacional, houve uma leitura dramática do Diálogo dos Mortos, a cargo do "Giz-en-scène", um concerto do Quinteto Experimental de Sopros da Escola de Música da UFRJ, a releitura do Filoctetes, de Heine Muller, a apresentação de O banquete de Platão em Martelo Agalopado, com Numa Ciro e a Universidade das Quebradas, além da rádio-novela $O$ lado obscuro do amor, pela Trupersa (UFMG).

As atividades administrativas correram regularmente e a Assembleia Geral Ordinária, ao lado de recompor os Conselhos e eleger a nova Diretoria, homologou decisão anterior segundo a qual os eventos bienais promovidos pela Sociedade seriam então denominados "Congressos da SBEC" e renumerados a partir do I Congresso Nacional de Estudos Clássicos, ocorrido em 1984.

O volume 23 de Classica, correspondente a 2010, por motivos econômicos e técnicos, correspondeu à concentração dos números 1 e 2, o mesmo acontecendo em 2011, com o volume 24 .

O XIX Congresso da SBEC, cujo tema foi "O futuro do passado", ocorreu em 2013, em Brasília, na UnB, contando com a parceria científica da Associação Portuguesa de 
Estudos Clássicos (APEC), que realizava simultaneamente o I Simpósio Luso-Brasileiro de Estudos Clássicos. Diferentemente do usual, o Congresso se iniciou com as apresentações concomitantes de 6 mesas de comunicações livres e duas sessões temáticas, às quais se seguiram mais 7 mesas de comunicações livres e uma sessão temática. Depois de um intervalo, houve apresentação de 20 pôsteres, seguida de uma palestra feita por João Canijo, da Escola Superior em Teatro e Cinema do Instituto Politécnico de Lisboa, e das apresentações simultâneas de 5 painéis, cada um com 3 ou 4 participantes, provenientes de diversas universidades: UFPel, Unicamp, Universidade Luterana do Brasil, USP, UFPB, Universidade de Coimbra, de Évora, de Lisboa, Università degli Studi di Salerno, Università di Roma. Em seguida, houve a sessão de abertura, com a apresentação, feita por Gabriele Cornelli, Presidente da SBEC, e a conferência de Celso Lafer, Presidente da FAPESP, "A lição dos clássicos: o futuro do passado". Nos dias subsequentes, a programação foi semelhante, apresentando-se mesas de comunicações livres, sessões temáticas, minicursos, painéis. Destacaram-se do conjunto, no segundo dia, o pronunciamento dos membros dos Grupos de Pesquisa "Gêneros Poéticos na Grécia Antiga" e "Laboratório de Estudos de Cerâmica Antiga"; no terceiro dia, as palestras de Helma Dik, da Chicago University, e de Ordep Serra, da UFBA, bem como a entrega do Prêmio SBEC de Dissertações e Teses aos vencedores de um concurso de teses. Um "Colóquio Internacional de Teoria Teatral" se estendeu por três dias e as "Conversas com autores", por quatro. No último dia, a palestra de encerramento ficou a cargo de Luís Fernando Veríssimo, palestrante convidado.

Como principal atividade recreativo-cultural, realizou-se o I Festival Internacional de Teatro Antigo, com várias representações que ocuparam toda a semana em diferentes horários, mas, principalmente, à noite. Houve uma leitura dramática do Filoctetes, feita pelo "Giz-en-scène", uma adaptação da peça Gota d'água, de Paulo Pontes e Chico Buarque, um recital de poesia antiga, a apresentação de uma versão modernizada dos Sete contra Tebas, uma performance intitulada Pandora na Linha, duas peças baseadas no Banquete, de Platão - $\grave{A}$ mesa e $O$ amante do dragão embriagado -, e, finalmente, a encenação de Medeia Furiosa, uma criação modernizada que correspondeu a uma continuação da tragédia de Eurípides.

A revista Classica passou nesse biênio por uma grande reformulação. Conforme disseram Renata Senna Garraffoni, editora da revista, e Gabriele Cornelli, Presidente da SBEC, no editorial do volume 25, n. 1/2, de 2012, a Diretoria da Sociedade "assumiu a tarefa de implementar mudanças administrativas e editoriais" em Classica a fim de fortalecer com isso o posicionamento acadêmico da SBEC. Estabeleceu-se uma parceria com a Annablume Editora, a revista migrou para a plataforma de gestão editorial SEER (Sistema Eletrônico de Editoração de Revistas) e o corpo da produção passou a contar com uma seção de artigos acoplada a um dossiê temático - nesse volume, o tema escolhido foi "Música na Antiguidade" -, mantendo, entretanto, as seções de resenhas e traduções. O layout da revista também se modificou. Em lugar da tradicional capa marrom, com a tonalidade que evocava a antiga cerâmica grega, optou-se por uma capa branca, com o título Classica em cores que variariam de volume para volume. A qualidade dos trabalhos apresentados, entretanto, o que é fundamental num periódico científico, se manteve inalterada em seu nível de excelência. 
Nova mudança se operou no número 26, correspondente a 2013, a partir do qual a revista voltou à semestralidade, apresentando dois números distintos por ano, com as mesmas seções usuais.

Em 2015, com o tema "Público e privado na Antiguidade", realizou-se em Mariana, Minas Gerais, o XX Congresso da SBEC, sediado no Instituto de Ciências Humanas e Sociais da UFOP.

Com afluência de participantes acima do esperado, o Congresso contou com a presença não só de interessados vinculados a unidades universitárias que tradicionalmente já participam de eventos da SBEC, tais como a UFMG, a UFJF, a UFU, a Unicamp, a UFPR, a UFC, a USP, a UNIFESP, a UNESP, a UnB, a UFRJ, a UFF, a UFRN, a UFPB, a UFES, a UFBA, as Universidades de Buenos Aires e do Chile, mas também com a de outras que se fizeram notar no evento, algumas das quais pela primeira vez: a UEA, a UFRRJ, a FEI, a UFPA, a PUC-GO, a UFSJ, a UEMG, a FATEC, a UFRR, a UNEB, a UFAL, a UFPE, a Unirio, a Universidad de Mar del Plata.

Na sessão de abertura do Congresso, Aloys Winterling, da Humboldt-Universität, de Berlim, pronunciou a conferência inaugural e, na de encerramento, Jacyntho Lins Brandão fez uso da palavra. No decorrer do evento, realizaram-se as atividades acadêmicas e administrativas. Em 8 mesas-redondas, 16 palestrantes se ocuparam de assuntos específicos e conduziram debates; 32 sessões de comunicações proporcionaram a apresentação de 125 trabalhos; 31 pôsteres foram exibidos e explicados; 4 minicursos foram oferecidos aos estudantes; 10 autores ou tradutores de livros que estavam sendo lançados participaram das "Rodas de autores", conversando com os presentes.

A principal atividade cultural oferecida aos congressistas no XX Congresso foi uma performance coletiva em que foi apresentada a tradução de Catulo 63 em galiambos portugueses. A proposta de uma tradução performativa desse poema se iniciara como um projeto integrado por alunos e docentes da UFPR, no âmbito dos estudos da disciplina Língua Latina $\mathrm{V}$, da graduação em Letras. O trabalho incorporou as noções de tradução literária como reescrita e de tradução performativa, a partir dos estudos e projetos desenvolvidos pelos dois docentes envolvidos, Rodrigo Tadeu Gonçalves e Guilherme Gontijo Flores. Além da tradução, o projeto incluiu a criação da performance do poema traduzido, que englobou canto, música e dança.

Nesse biênio foram divulgados na nova página da SBEC os volumes 27, n. 1 e 2, e 28, n. 1 e 2, correspondentes a 2014 e 2015.

O XXI Congresso da SBEC ocorreu em 2017, em São Paulo, nas dependências da USP, abrigando o I Colóquio Internacional sobre Xenofonte e tendo como tema "Arte, política e cidadania na Antiguidade".

$\mathrm{Na}$ sessão de abertura, após as palavras iniciais de boas-vindas, foi feita uma homenagem a ilustres pesquisadores associados à SBEC, que haviam falecido no biênio anterior, deixando muitas saudades e a lembrança de sua capacidade, competência e valor: Professores Doutores Marcelo Pimenta, da UFMG, homenageado por Jacyntho Lins Brandão; Anna Lia A. de Almeida Prado, da USP, por Filomena Hirata, e Ariovaldo 
Augusto Peterlini, também da USP, por Zelia de Almeida Cardoso. As atividades acadêmicas se desenvolveram durante toda a semana nos períodos da manhã e da tarde, tendo havido apresentações de 10 conferências, pronunciadas por pesquisadores convidados: Paula da Cunha Corrêa, Roberto Bolzani Filho, Paulo Martins e Alexandre Pinheiro Hasegawa, da USP; Pedro Paulo Abreu Funari, da Unicamp; Fábio Faversani, da UFOP; Luisa Severo Buarque de Holanda, da PUC-RJ; Lucia Athanassaki, da University of Crete; Luigi Galasso, da Università Cattolica del Sacro Cuore; e Ewen Bowie, da University of Oxford. Foram apresentadas 28 sessões de comunicações e 14 mesas de Grupos de Pesquisa, com cerca de 270 trabalhos no total. Foram oferecidos aos estudantes 8 minicursos regulares e um especial, conduzido por Luigi Galasso, de Milão. Como parte das atividades acadêmicas, houve ainda lançamentos de livros, exibição do documentário Pólis: viver na cidade grega antiga, e apresentação do grupo Pecora Loca.

As atividades administrativas se desenrolaram como o esperado e a Assembleia Geral Ordinária recompôs os Conselhos e elegeu a nova Diretoria, com Tatiana Oliveira Ribeiro (UFRJ) como Presidente.

Nesse biênio foram divulgados na página da SBEC os volumes 29, n. 1 e 2, e 30, n. 1 e 2, de Classica, correspondentes a 2016 e 2017, bem como o volume 31, n. 1 e 2, correspondente a 2018.

As dificuldades que marcaram a história de Classica, em seu início, sobretudo relacionadas com questões financeiras e com a falta de pessoal especializado para os serviços técnicos, foram sendo superadas. Os organizadores responsáveis pelos volumes publicados ultrapassaram os óbices e a revista está chegando hoje ao número 2 do volume 33.

Estamos, finalmente, em nossos dias. Lançamos os olhos para trás e contemplamos com a visão da memória tudo o que se passou. A SBEC completa, em 2020, 35 anos de existência; Classica chegou aos 30. Nesse lapso temporal, quanta coisa aconteceu em nossa área de pesquisa, docência e trabalho!

Durante todos esses anos, em que se concretizaram dezenas e dezenas de atividades culturais e eventos, a SBEC apoiou também as iniciativas culturais promovidas por numerosas unidades universitárias brasileiras em prol dos estudos clássicos. Muitos de seus sócios nelas marcaram presença como convidados ou participantes. Compareceram em muitas ocasiões à Semana de Estudos Clássicos da UFRJ, que chega, em 2019, à sua $38^{a}$ ocorrência, sendo, portanto, mais antiga do que os eventos da própria SBEC; ou ao Seminário de Estudos Clássicos da UFF, cuja $26^{a}$ versão também ocorre agora; ou ao Congresso Nacional de Letras Clássicas e Orientais que vem sendo promovido pela UERJ há 18 anos; ou, ainda, às "Semanas" de Estudos Clássicos, organizadas periodicamente pela UNESP desde 1986, no campus de Araraquara, e também no de Rio Preto, pela UFJF desde 1988. Em 2011, com apoio da SBEC, conferências pronunciadas por docentes da própria Universidade e por pesquisadores convidados, durante a XXIII Semana de Estudos Clássicos, realizada na UNESP-Araraquara, cujo tema era "Cultura clássica: inter-relações e permanência", foram coligidas no livro Permanência clássica: visões contemporâneas da Antiguidade greco-romana, organizado por Brunno V. G. Vieira e Márcio Thamos, e publicado em São Paulo, pela Escrituras Editora. 
Membros da SBEC têm apoiado as atividades da UFJF e da UFC, que, há 32 e 25 anos, respectivamente, promovem suas "Semanas de Estudos Clássicos". Têm estado na USP, onde se realizaram, desde os anos 90 do século passado, os "Encontros SBEC" e os "Encontros Acadêmicos", promovidos pelo MAE-USP e pela FFLCH, como também as "Semanas de Estudos Clássicos e Educação", organizadas pela Faculdade de Educação, e as dezenas de outros eventos que têm sido levados a termo constantemente, inclusive com o apoio de Programas de Pós-Graduação. Foram assíduos no acompanhamento das atividades da Unicamp, que não só mantém estudos especializados nas áreas de graduação e pós, como promove numerosas e variadas atividades por meio do CEC-IEL (Centro de Estudos Clássicos) e do CPA-IFCH (Centro de Estudos e Documentação do Pensamento Antigo Clássico, Helenístico e sua Posteridade Histórica), entre as quais se ressaltam a promoção de eventos, a manutenção da revista PhaoS e da Revista de Estudos Filosóficos e Históricos da Antiguidade, como também a tradução de obras clássicas e sua publicação pela Editora da Unicamp. Membros da SBEC estiveram muitas vezes presentes na UFPel, onde há 19 anos ocorrem as "Jornadas de História Antiga-Estudos Clássicos no RS”, e na UFMG, onde, além dos estudos clássicos ministrados em nível de Graduação e Pós, são realizados anualmente vários eventos no âmbito da FALE e da FAFICH, destacando-se, desde 2008, o periódico semestral eletrônico, Nuntius Antiquus, que publica artigos científicos tendo como temática culturas e literaturas da Antiguidade e da Idade Média.

Em muitas outras unidades universitárias do país há espaços reservados aos estudos clássicos na programação cultural, tendo tido, elas também, o apoio da SBEC. Na UFPB, além de um curso de graduação em Letras Clássicas, criado em 2009, há dois grupos de pesquisa voltados para o estudo de autores antigos, credenciados pelo CNPq, o GREC (Grupo de Estudos Clássicos e Literários) e o NEALC (Núcleo de Estudos Aprofundados de Línguas Clássicas). Ambos contam com a participação de docentes e alunos de Graduação e de Pós que preparam trabalhos para publicação. Em 2014, em rememoração ao segundo bimilenário da morte de Augusto, a UFPB promoveu o $1^{\circ}$ Encontro do Nordeste de Estudos Clássicos, "14-2014: Dois milênios augustos", que ocorreu concomitantemente com o IV Encontro de Professores de Latim, contando com a presença de membros da SBEC. No Amazonas, em 2016, foi promovida pela UEA a I Semana Internacional de Estudos Clássicos do Amazonas, congregando interessados provenientes não só de outras universidades locais, como a UFAM e a Fametro, mas também de Parintins (Cesp), Tefé (Cest), Tabatinga (Cestb), da Universidade de Roraima (UFRR) e de numerosas outras unidades universitárias do país, que prestigiaram o evento com sua presença. Em 2018, a EAM realizou a II Semana Internacional de Estudos Clássicos do Amazonas, durante a qual também ocorreu o Fórum da ABPL (Associação Brasileira dos Professores de Latim). Nesse mesmo ano, a Universidade Federal do Amazonas promoveu o I Simpósio Nacional de Estudos Clássicos do Amazonas, integrado ao IV Seminário de Linguística. No Pará, têm sido organizados anualmente os "Seminários de Estudos Clássicos e Filosofia Antiga da Universidade Federal do Pará". No Maranhão, há um Grupo de Estudos Filosóficos que se dedica à História da Filosofia e aos Estudos Clássicos, promovendo, em São Luís, reuniões, palestras e cursos, além de 
manter um site que abriga e-books e artigos sobre filosofia e educação. Na UFPI, durante o IV Encontro de Letras da Universidade Estadual do Piauí, ocorrido em 2018, no Campus de Picos, houve espaço para os estudos clássicos, como o indica a própria conferência de abertura, pronunciada pelo Prof. Kássio Gomes: "Dos clássicos aos contemporâneos: um breve passeio pela história da poesia”. Em Pernambuco, a Associação Nacional de HistóriaSeção Pernambuco mantém vínculos com a SBEC e com a ABREM (Associação Brasileira de Estudos Medievais). Em Sergipe, a UFS, além de ter um Grupo de Estudos em Filosofia e Literatura, que promove "Colóquios de Filosofia e Literatura" e "Seminários de Pesquisa", com publicação de Anais, e uma página na internet para divulgação e registro das atividades do grupo, mantém também um "Laboratório de Estudos da Antiguidade e do Medievo (Vivarium)", inserido no Departamento de História e vinculado ao Programa de PósGraduação, organizando "Semanas de Estudos Clássicos" desde 2008. Na Bahia, a UFBA propôs com sucesso, em 2012, por iniciativa do grupo de pesquisa NALPE, a realização do I Encontro de Estudos Clássicos da Bahia, do qual resultou o livro Mosaico clássico: variações acerca do mundo antigo, organizado por José Amarante e Luciene Lages e publicado em Salvador, em 2012, pela própria UFBA. No Espírito Santo, a UFES realiza anualmente as "Jornadas de Estudos Clássicos". A Universidade Federal de Uberlândia promoveu, em 2017, a I Jornada de Escritores da Roma Antiga: Sêneca; a PUC Goiás, em 2018, o Primeiro Ciclo de Estudos Clássicos entre Arqueologia e História. A UFPR mantém bacharelado e licenciatura em latim ou grego, ou bacharelado e licenciatura duplos, em latim e português ou em grego e português. A Área de Letras Clássicas oferece aos alunos um "Painel de Clássicas", onde são colocados avisos sobre as disciplinas da área, notícias relacionadas com os estudos clássicos, no Brasil e no Exterior, e informações variadas sobre o mundo antigo que possam interessar os jovens. Docentes e pesquisadores da Universidade comparecem com grande frequência aos eventos promovidos pela SBEC ou por outras universidades. A Universidade de Brasília promove regularmente os "Seminários Internacionais Archai", realizados pela Cátedra UNESCO Archai do Programa de Pós-Graduação em Metafísica, e os Seminários Internacionais "Eudoro de Souza", pelo Núcleo de Estudos Clássicos "Eudoro de Souza”. A Cátedra UNESCO Archai da Universidade de Brasília promoveu a Primeira Summer School Archai - Ontologias Antigas, na Ilha de Itaparica, em 2017, e a Segunda Summer School Archai - (re)traduzindo os clássicos, cujas aulas foram ministradas pelo Prof. Alberto Bernabé, da Universidad Complutense, de Madri, em Florianópolis, em 2018.

Numerosos Grupos de Pesquisa, certificados pelo CNPq e por Universidades às quais estão vinculados, dedicam-se a estudos sobre as sociedades antigas e são filiados à SBEC, realizando atividades culturais, tais como reuniões, seminários, colóquios, e promovendo publicações. Até 2019, eram eles: Ápeiron: Estudos em Física e Metafísica (IFTM); ATRIVM - Espaço Interdisciplinar de Estudos da Antiguidade (UFMS); Cátedra UNESCO ARCHAI: As Origens do Pensamento Ocidental (UnB); CEIA - Centro de Estudos Interdisciplinares da Antiguidade (UFF); CirceA - Círculo de Estudos da Antiguidade (UFJF); ERA - Estudos Retóricos e Argumentativos (PUC SP); Estudos da Tradição Clássica (UNIFESP - Campus de Guarulhos); Estudos sobre o jambo, a elegia e a poesia mélica na Antiguidade Clássica 
(USP); Gêneros poéticos na Grécia Antiga: tradição e contexto (USP); GPEL - Grupo de Pesquisa sobre Ensino de Latim (Unicamp); Grupo de Tradução de Teatro (UFMG); Grupos subalternos e práticas populares na Antiguidade (USP); GTA - Estudos sobre o Teatro Antigo (USP); IAC - Imagens da Antiguidade Clássica (IAC-USP/PROAERAUFRJ); LEAO - Laboratório de Estudos da Antiguidade Oriental (UFRGS); LABHAM - Laboratório de História Antiga e Medieval (UFPI); Laboratório OUSIA de Estudos em Filosofia Clássica (UFRJ); LHIA - Laboratório de História Antiga (UFRJ); LIMES Fronteiras Interdisciplinares da Antiguidade e suas Representações (UFES); LINCEU: Visões da Antiguidade Clássica (UNESP - Câmpus de Araraquara); NEA: Núcleo de Estudos da Antiguidade (UERJ-Campus Maracanã); Núcleo de Cultura Clássica (UFC); PROAERA - Programa de Estudos em Representações da Antiguidade (UFRJ); República das Letras Estudo de Textos Renascentistas em Latim (USP); Rhetor - Grupo de Estudos de Retórica e Oratória Antiga (UnB); SBP - Sociedade Brasileira de Platonistas; TAPHOS - Grupo de Pesquisa em Práticas Mortuárias no Mediterrâneo Antigo (MAE-USP).

Em março de 2019, a SBEC realizou o I Seminário dos Grupos de Estudo da SBEC, na Universidade Federal do Estado do Rio de Janeiro (UNIRIO), campus da Praia Vermelha, convidando os líderes para falarem sobre os Grupos e apresentarem trabalhos.

Ao lado de apoiar iniciativas de unidades universitárias, a SBEC sempre participou ativamente de eventos promovidos por outras entidades, tais como ANPOLL, ANPOCS, ANPOF, ANPUH, GEL, CELLIP, ABA, AADEC, PARSA, e por universidades de outros países que mantêm relações com o Brasil: Argentina, Uruguai, Chile, Venezuela, Colômbia, Estados Unidos, Canadá, México, Cuba, Portugal, Espanha, França, Inglaterra, Suíça, Itália, Grécia. Delegações da SBEC têm também participado regularmente dos Congressos quinquenais da FIEC.

Aguardando agora a realização do XXIII Congresso da SBEC, a ocorrer na UFC em 2021, celebramos neste número de Classica alguns dos frutos do XXII Congresso da SBEC, realizado na UFJF de 2 a 6 de setembro de 2019, com o tema 'Antiguidade: Desejo e Liberdade'. Chegamos ao fim de nosso depoimento, reiterando nosso infinito apreço à Sociedade Brasileira de Estudos Clássicos, pelo que é e por tudo que tem feito por meio de seus Diretores, de seus sócios, de seus pesquisadores, de seus convidados, e também dos milhares de estudantes que constantemente participam das atividades que têm sido promovidas - gente que viverá o amanhã e que resguardará para sempre, esperamos, a valiosa herança cultural do passado. 